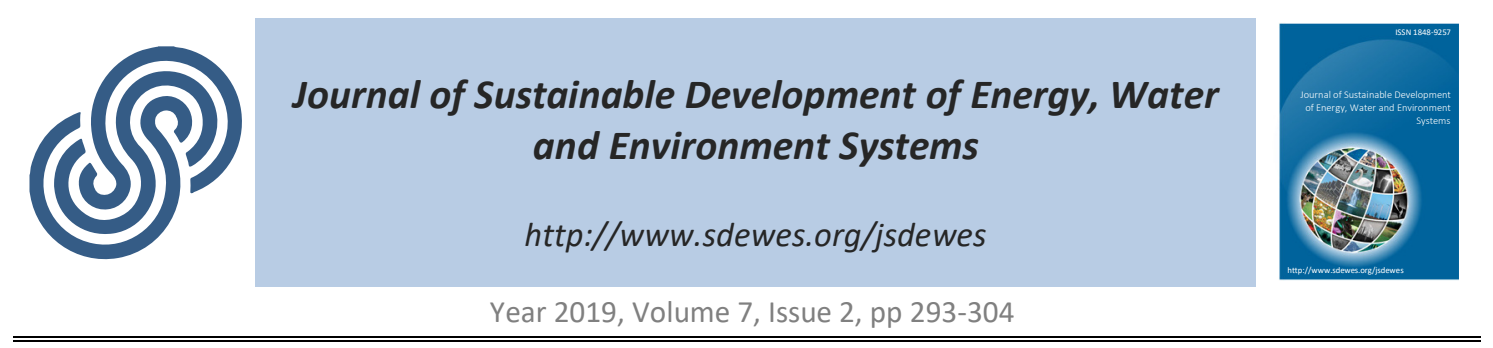

\title{
Refrigerant Options in the Near Future
}

\author{
Vedran Zanchi ${ }^{1}$, Luka Boban $^{2}$, Vladimir Soldo ${ }^{* 3}$ \\ ${ }^{1}$ Faculty of Mechanical Engineering and Naval Architecture, University of Zagreb, Ivana Lučića 5, \\ Zagreb, Croatia \\ e-mail: vedran.zanchi@fsb.hr \\ ${ }^{2}$ Faculty of Mechanical Engineering and Naval Architecture, University of Zagreb, Ivana Lučića 5, \\ Zagreb, Croatia \\ e-mail: luka.boban@fsb.hr \\ ${ }^{3}$ Faculty of Mechanical Engineering and Naval Architecture, University of Zagreb, Ivana Lučića 5, \\ Zagreb, Croatia \\ e-mail: vladimir.soldo@fsb.hr
}

Cite as: Zanchi, V., Boban, L., Soldo, V., Refrigerant Options in the Near Future, J. sustain. dev. energy water environ. syst., 7(2), pp 293-304, 2019, DOI: https://doi.org/10.13044/j.sdewes.d6.0250

\begin{abstract}
Regulation EU no. 517/2014 on fluorinated greenhouse gases (the F-gas regulation) and today's research in the refrigeration and air-conditioning technology and heat pumps are increasingly focused on the use of natural refrigerants such as ammonia, carbon dioxide and hydrocarbons. Besides having zero ozone depletion potential, refrigerants should have their global warming potential as low as possible. In a way, the said Regulation promotes the use of sustainable technologies and sustainable natural refrigerants in refrigeration systems. The paper gives an overview, application and basic properties of refrigerants in refrigeration equipment and heat pump systems divided in different categories. The emphasis is on natural refrigerants that are gradually being used as a replacement for refrigerants from the hydrofluorocarbon group. Furthermore, the hydrofluorocarbon refrigerant group is analyzed in the context of F-gas regulation. Also, the hydrofluoro-olefin refrigerant group, which is currently being used in automotive cooling systems, is listed. The mentioned refrigerant group is widely recognized as the next generation of refrigerants due to its favourable environmental properties and cost-effectiveness. The paper also contains total equivalent warming impact number calculations of cooling plants for cooling buildings with a known cooling load. The comparison is given for different types of refrigerants with the purpose of better understanding their ecological impact. Results indicate that the natural refrigerants are the best option since their ecological impact is negligible.
\end{abstract}

\section{KEYWORDS}

F-gas regulation, Natural refrigerants, Fluorinated refrigerants, Application sectors, Total equivalent warming impact.

\section{INTRODUCTION}

Following the phase-out of Ozone-Depleting Substances (ODS) such as Chlorofluorocarbons (CFC) and Hydrochlorofluorocarbons (HCFC) under the Montreal Protocol on Substances that Deplete the Ozone Layer in 1987, the use of

\footnotetext{
* Corresponding author
} 
Hydrofluorocarbons (HFC) as main replacements has been increasing. According to the European Commission, F-gas emissions have risen by $60 \%$ since 1990, in contrast to all other greenhouse gases whose emissions have been reduced [1]. Although HFC substances do not affect the ozone layer, they have an adverse effect on the global climate. Furthermore, their Global Warming Potential (GWP) is defined for the time interval of 100 years, but given the fact that they have a much shorter atmospheric lifetime, such as 20 years, the real GWP value is much higher. For instance, R134a has an atmospheric lifetime of 14-16 years. Its GWP over 100 years is 1,430 while the GWP over 20 years, which is a much better indicator to its actual existence in the atmosphere, is 3,830. Under the Kyoto Protocol of 1997, the European Union has committed to reduce greenhouse gas emissions by $80-95 \%$ by 2050 in reference to the 1990 levels. To achieve the desired goal, the European Commission adopted a plan for moving to a competitive low-carbon economy in 2050, which includes cost-effective reductions in certain sectors, in particular the reduction of F-gas emissions which should be reduced by over $70 \%$. Due to the increase in fluorinated greenhouse gas emissions, the European Union adopted two key legislative acts - the MAC Directive which relates to mobile air conditioning systems, and the so called F-gas Regulation. After an evaluation in 2011, it was decided that further action is necessary and the revised F-gas Regulation came into force in January 2015.

Regulation (EU) no. 517/2014 (F-gas Regulation) replaces the existing Regulation (EC) no. 842/2006 and regulates the treatment with fluorinated greenhouse gases throughout their life cycle, from production to disposal at the end of use [2]. One of the key elements of the Regulation is the phase-down of HFC's with a reduction target of $79 \%$ by 2030 (compared to the average levels in 2009-2012 period on the EU market). Producers and importers of F-gases are allocated annual quotas of HFC's that allow them to place a certain amount on the market and then those quotas are gradually reduced until 2030. This in turn means that by 2030 the average GWP of HFC's will fall from today's 2,000 to about 400 across all sectors. Natural refrigerants are expected to play a major role in achieving this target. In addition, the Regulation introduces certain restrictions on the use of HFC's with a GWP above a set threshold. For instance, the use of HFC's with a GWP of 2,500 or more, to service refrigeration equipment with a charge of 40 tonnes of Carbon dioxide $\left(\mathrm{CO}_{2}\right)$ equivalent or more, will be prohibited starting from January $1^{\text {st }}$ of 2020 [3]. Also, new equipment in the commercial sector is expected to operate with refrigerants with a GWP below 150 by 2022. Furthermore, the Regulation aims for increased leakage control for systems containing high GWP refrigerant, and new demands on the training of professional personnel involved in handling F-gas refrigerants.

The report on GWP limitations imposed by the Regulation addresses the need for alternative refrigerants and explores the possibility of new Hydrofluorocarbon/Hydrofluoro-olefin (HFC/HFO) mixtures but ultimately concludes that the application is limited due to their flammability [4]. Total Equivalent Warming Impact (TEWI) analysis from [3] shows that in terms of best life performance, the best performing systems are the ones with R290, R600a and R717. However, it is further argued that there are reported concerns about the availability of components which consequently limit their immediate future application. On the other hand, the paper on natural refrigerants [5] is primarily concerned with protection of life on the planet for future generations. Its emphasis is on their near zero effect on the environment, combined with the fact that natural refrigerants are miscible with both mineral oil used in CFC and Polyolester (POE) oils used in HFC systems. Good lubricating properties are essential for compressor efficiency. A review of R1234ze(E) points out the many advantages of new HFO refrigerants and their potential to replace R134a, R404A, R410A and R22 directly or with minor system modifications [6]. The paper on heating performance of various 
zeotropic and azeotropic mixtures concludes that the best performing refrigerants are R410A and R507A but doesn't take into consideration their higher GWP values which in turn make them undesirable for future application [7]. A comparative study on the risks associated with using hydrocarbons proposes R290 as an alternative to HCFC R22 in room split air conditioners [8]. Also, another paper which studies performance factors concludes that a refrigerant mixture of Hydrocarbons (HC) and R134a is an appropriate ecologically energy efficient alternative to substitute R22 in air conditioning applications [9]. Studies on the HFC R404A alternatives [10, 11], albeit temporary, propose various blends, such as R407A and R407F as viable retrofit options. Moreover, additional studies $[12,13]$ list HFO based blends - R448A and R449A, as energy efficient replacements with a GWP reduction of $70 \%$ when compared to R404A. A detailed research on heat exchanger volumes is focused on new technological solutions to reduce refrigerant charge, for the purpose of safety concerns regarding the usage of R290 as an alternative to R404A in a commercial freezer [14]. The paper on low GWP alternatives [15] presents system simulation tests for a residential reversible heat pump system with R447B and $\mathrm{R} 452 \mathrm{~B}$ as substitutes for R410A. The article also reports certain theoretical evaluations of replacements for R134a, which include the HFO refrigerants R1234yf and R1234ze, with the latter already accepted as a long term industry solution for chillers. Another study [16], motivated by the increasing pressure of new regulations imposed on the industry in the U.S., provides a detailed analysis of R32 as an ideal initial candidate to replace R410A, at least until 2020. A similar study concerning the use of R32 [17], provides the same results, with the emphasis on good performance results, which can be further enhanced by component optimization. The paper on low-GWP R134a alternatives [18], lists R290, R600a, R1234ze(E), R1234yf and R152a as potential candidates. It concludes that R152a and R1234yf are the best drop-in alternatives, albeit taking into account the corresponding safety requirements, as R152a and R1234yf have ASHRAE Safety Classifications of A2 and A2L, respectively. Another research [19] on R134a substitutes is more focused on HC options such as R290 and R600a which could provide comparable system performance for residential heat pump water heaters. In contrast, another study [20] leans more toward HFO options, which are presented as adequate drop-in replacements for R134a. Further study on HFO options [21] presents R1234yf and two additional HFO blends - R444A and R445A, as suitable options for mobile air conditioning systems instead of R134a.

The aim of the paper is to introduce the reader to the current and future refrigerant options. Critical review of available literature on natural and fluorinated refrigerants has been conducted for different application sectors. Emphasis is given on refrigerant replacements that require minor system modifications while preserving system performance. TEWI analysis is given as a way of better understanding the key differences between natural and fluorinated refrigerants and their ecological impact.

\section{METHODS}

The methods for conducting the study were based on the evaluation of the various environmental protocols and regulations that are in place, and in turn, their effect on the entire refrigeration industry, specifically on the usage of certain refrigerant groups. Moreover, a review of the recent research concerning refrigerant options has been analysed and put into perspective regarding on how it affects various industry sectors. Analysis was based on the refrigerants that are currently in use or were used in the past, and the ones which are expected to be deployed on a wider scale due to numerous studies and technological advancements. Furthermore, the study shows that in the recent years, the industry was able to overcome the technical challenges related to the lack of interest and awareness, and adapt to the current regulations in effect. Methodology has shown that natural refrigerants that were once used in the past, are to be used again, which thus 
confirms the hypothesis of reliable and eco-friendly refrigerant options that are to be permanently introduced in the future. Table 1 contains the characteristics of various refrigerants, many of which are in use today and will be used on a permanent basis in the near future.

Table 1. Thermophysical, environmental, and safety properties of different refrigerants

\begin{tabular}{|c|c|c|c|c|c|c|c|c|c|c|}
\hline Refrigerant & R717 & R744 & R290 & R600a & R22 & $\mathrm{R} 134 \mathrm{a}$ & R410A & $\mathrm{R} 32$ & $\mathrm{R} 404 \mathrm{a}$ & R1234ze \\
\hline Group & Inorganic & $\mathrm{CO}_{2}$ & $\mathrm{HC}$ & $\mathrm{HC}$ & $\mathrm{HCFC}$ & $\mathrm{HFC}$ & $\mathrm{HFC}$ & $\mathrm{HFC}$ & $\mathrm{HFC}$ & HFO \\
\hline ODP & 0 & 0 & 0 & 0 & 0,055 & 0 & 0 & 0 & 0 & 0 \\
\hline $\mathrm{GWP}_{100}$ & 0 & 1 & 3 & 3 & 1,700 & 1,430 & 1,980 & 675 & 3,922 & 6 \\
\hline $\begin{array}{l}\text { ASHRAE Safety } \\
\text { Classification }\end{array}$ & B2L & $\mathrm{A} 1$ & A3 & A3 & A1 & $\mathrm{A} 1$ & $\mathrm{~A} 1$ & $\mathrm{~A} 2 \mathrm{~L}$ & A1 & $\mathrm{A} 2 \mathrm{~L}$ \\
\hline $\begin{array}{l}\text { Molecular mass } \\
{[\mathrm{kg} / \mathrm{mol}]}\end{array}$ & 17.03 & 44 & 44.1 & 58.12 & 86.47 & 102.03 & 72.59 & 52 & 97.6 & 114 \\
\hline $\begin{array}{c}\text { Critical temperature } \\
{\left[{ }^{\circ} \mathrm{C}\right]}\end{array}$ & 135.25 & 31 & 96.7 & 134.7 & 96.2 & 101 & 70.17 & 78.11 & 72.14 & 109.4 \\
\hline Critical pressure [bar] & 113.3 & 73.78 & 42.5 & 36.4 & 49.9 & 40.6 & 47.7 & 57.8 & 37.4 & 36.36 \\
\hline $\begin{array}{c}\text { Evaporating } \\
\text { temperature }\left(p_{\text {atm }}\right)\left[{ }^{\circ} \mathrm{C}\right]\end{array}$ & -33.3 & -78.4 & -42.4 & -11.6 & -40.8 & -26.1 & -51.6 & -51.7 & -46.6 & -18.9 \\
\hline $\begin{array}{l}\text { Evaporating pressure } \\
\quad\left(-15^{\circ} \mathrm{C}\right)[\mathrm{bar}]\end{array}$ & 2.36 & 22.91 & 2.92 & 0.89 & 2.96 & 1.64 & 4.82 & 4.88 & 3.72 & 1.2 \\
\hline $\begin{array}{l}\text { Liquid density }\left(30{ }^{\circ} \mathrm{C}\right) \\
\qquad\left[\mathrm{kg} / \mathrm{m}^{3}\right]\end{array}$ & 595.2 & 593.3 & 484.4 & 544.3 & 1,171 & 1,187 & 1,035 & 939.6 & 1,021 & 1,184 \\
\hline $\begin{array}{c}\text { Gas density }\left(-15^{\circ} \mathrm{C}\right) \\
{\left[\mathrm{kg} / \mathrm{m}^{3}\right]}\end{array}$ & 1.97 & 60.72 & 6.5 & 2.49 & 12.9 & 8.29 & 18.43 & 13.34 & 18.57 & 6.57 \\
\hline $\begin{array}{l}\text { Specific latent heat } \\
\left(-15^{\circ} \mathrm{C}\right)[\mathrm{kJ} / \mathrm{kg}]\end{array}$ & $1,312.8$ & 270.93 & 394.4 & 369.8 & 216.5 & 209.5 & 237.6 & 337.34 & 177.7 & 195 \\
\hline $\begin{array}{l}\text { Volumetric cooling } \\
\text { capacity }\left[\mathrm{kJ} / \mathrm{m}^{3}\right]\end{array}$ & $2,214.3$ & $9,805.67$ & $1,897.4$ & 688 & $2,178.8$ & $1,285.3$ & $3,243.7$ & $3,548.1$ & $2,250.7$ & 928 \\
\hline
\end{tabular}

\section{Industrial refrigeration sector}

From a regulatory standpoint, this sector has already shifted to eco-friendly refrigerants.

Ammonia (R717) has been a well-known refrigerant in large scale industrial applications for more than 120 years [5]. It has excellent thermodynamic and transport properties, and consequently high energy efficiency in refrigeration systems. Today, more than $90 \%$ of large industrial refrigeration facilities in Europe use R717 as a refrigerant [1]. Moreover, it is used in food processing and cold storage industries, ice rinks, wineries, breweries, and large scale air conditioning for universities, office buildings and airports. In numerous applications it exceeds R22, which is considered to be the most effective refrigerant from the HCFC group. Since the developing countries are still using R22, ammonia could potentially serve as a viable replacement refrigerant in the future. What limits its application in other sectors are safety concerns, incompatibility with copper materials, higher gas discharge temperatures and the need for open type compressors [22]. For instance, since there are no compressors small enough, it is not suitable for domestic heat pump systems [3]. Table 2 shows the ratio between the thermophysical properties of R717 and R22. For a certain cooling effect, systems using R717 have smaller piping dimensions, less refrigerant charge, and the pressure drops are considerably smaller, which is especially useful in long, branched systems.

Table 2. Thermophysical property ratio of R717 and R22 [23]

\begin{tabular}{cccccc}
\hline $\begin{array}{c}\text { Thermophysical } \\
\text { property }\end{array}$ & $\begin{array}{c}\text { Specific heat } \\
\text { capacity } \\
\left(c_{\mathrm{p}}\right)[\mathrm{kJ} / \mathrm{kgK}]\end{array}$ & $\begin{array}{c}\text { Specific latent heat } \\
(r)[\mathrm{kJ} / \mathrm{kg}]\end{array}$ & $\begin{array}{c}\text { Liquid thermal } \\
\text { conductivity } \\
(\lambda)[\mathrm{W} / \mathrm{mK}]\end{array}$ & $\begin{array}{c}\text { Dynamic viscosity } \\
(\mu)[\mathrm{Pas}]\end{array}$ & $\begin{array}{c}\text { Liquid density } \\
(\rho)\left[\mathrm{kg} / \mathrm{m}^{3}\right]\end{array}$ \\
\hline R717/R22 & $4 / 1$ & $6 / 1$ & $5.5 / 1$ & $0.8 / 1$ & $0.5 / 1$ \\
\hline
\end{tabular}




\section{Domestic refrigeration sector}

Following the restrictions of F-gas regulation, which ban the use of refrigerants in the domestic sector with a GWP of 150 or more from 2015, R600a was introduced as a replacement for R134a. R134a is one of the most commonly used HFC refrigerants which was developed for the purpose of replacing R12. Since then, it has had a wide application across many different refrigeration sectors, but now it is being replaced due to proposed HFC phase down steps. On the other hand, HC's are excellent refrigerants in many ways - energy efficiency, critical point, solubility, transport and heat transfer properties [5]. Furthermore, they are fully chemically compatible with almost all of the lubricants used in the refrigeration systems, but special care must be taken due to the greater solubility which in turn could cause oil dilution. The most important concern regarding the application of HC's is their flammability, safety classification A3 (Table 1). Nevertheless, more than 700 million HC-based domestic refrigerated appliances worldwide are proving that HC's can be safely used [1]. The study on the risk associated with using R600a in domestic refrigerators shows that the risk is negligible [8]. Moreover, R1270 and R290 can be used in a mixture with R134a to produce an efficient alternative refrigerant to substitute R22 in older systems, more specifically in developing countries [9]. R134a is added in the mixture in order to reduce the flammability of HC's.

\section{Commercial refrigeration sector}

Commercial refrigeration is an example of a sector where the F-gas Regulation has had a very prominent impact [1]. This is due to an upcoming ban on the use of HFC's with a GWP higher than 150 as of January 2022 in multipack centralised refrigeration systems for commercial use with a rated capacity of $40 \mathrm{~kW}$ or more, except in the primary refrigerant circuit of cascade systems where fluorinated greenhouse gases with a GWP of less than 1,500 may be used [2]. The greatest impact of the Regulation in the near future will be on users of R404a (R143a/R125/R134a - 52/44/4), which is the global industry standard HFC refrigerant for commercial refrigeration in both small and large systems [10]. It is subject to phase-out in all sectors since it has a GWP value of 3,922. One of the possible non-flammable replacements are R407F (R125/R32/R134a - 30/30/40) and R407A (R125/R32/R134a - 40/20/40), but it is important to note that these refrigerants are only temporary alternatives due to medium - high values of GWP $-1,824$ and 2,107, respectively [11]. Another non-flammable option is the recently developed R448A which offers greater GWP reduction. Despite having higher Coefficient of Performance (COP) values, it has a lower cooling capacity which implies higher run time in supermarket systems, so it is more recommended to use this refrigerant in redesigned systems [12]. In addition, a recent study [13] states that R449A is a viable retrofitting option for R404A supermarket refrigeration systems due to comparable COP's and much better TEWI numbers. Also, there is the possible use of R290 as a substitute for R404a in the sector of light commercial refrigeration, which could potentially reduce the energy consumption by 34\% [14]. Even though R290 is quite different from a thermodynamic point of view, its major advantage is the value of latent heat which is around two times greater, which in the turn reduces the mass flow rate in the system.

The primary reliable natural refrigerant option in this sector is $\mathrm{CO}_{2}(\mathrm{R} 744)$, whose usage has become increasingly popular over the last few years. After the interest in $\mathrm{CO}_{2}$ virtually disappeared in the 1950's, the idea of using it again was brought up by Lorentzen in the late 1980's [24]. It represents an excellent alternative among the natural refrigerants, especially in applications such as these, where the toxicity and flammability of R717 and HC's may be a problem [25]. $\mathrm{CO}_{2}$ can also be found in small to medium sized industrial refrigeration plants, either as a sole refrigerant or in combination with $\mathrm{R} 717$ in cascade systems. The biggest challenge in $\mathrm{CO}_{2}$ refrigeration system technology 
is dealing with a unique critical point of about $31{ }^{\circ} \mathrm{C}$ with a corresponding absolute pressure of 74 bar [24]. Therefore, pressures in refrigeration systems with $\mathrm{CO}_{2}$ are usually up to 10 times higher than those systems using R717 or R404A. Moreover, because of such distinct properties, most modern $\mathrm{CO}_{2}$ systems operate in transcritical mode. In fact, the $\mathrm{CO}_{2}$ transcritical refrigeration systems have become the mainstream-cutting edge HFC-free technology for the food retail sector [1]. The number of European stores using $\mathrm{CO}_{2}$ transcritical systems have tripled between the years 2013-2016 [1], with the effect most pronounced in Western and Northern Europe.

\section{Air-conditioning and heat pumps sectors}

The increase of new HFC-free products in these sectors is not very pronounced, partly due to the fact that there are no bans for HFC's with GWP > 150 (except moveable room AC by 2020). The only major ban by 2025 will be on single split AC systems with a refrigerant charge of less than $3 \mathrm{~kg}$, containing fluorinated greenhouse gases with GWP $>750$.

R410A, which was introduced as a replacement for R22, is currently widely used in air-conditioning applications ranging from residential unitary air-conditioning, heat pump systems to large commercial chillers [19]. With a GWP of 1,924, it has thus become a target of the Regulation. In that context, several low-GWP R410A replacements are under evaluation by the industry. The blends in question are R447B (R32/R125/R1234ze - 68/8/24) and R452B (R32/R125/R1234yf - 67/7/26). Both of these refrigerants have A2L ASHRAE classification and GWP's of 714 and 675, respectively. Theoretical system simulations in a R410A reversible heat pump indicate that both of the low GWP alternatives can match the performance of R410A without significant system modifications for ambient temperatures below $35^{\circ} \mathrm{C}$ and can show $3 \%$ to $4 \%$ higher efficiency at elevated ambient temperatures [15]. In addition, R32 as a pure substance can also be used as a reliable R410A replacement. Its GWP of 675 and A2L classification make it a favorable candidate for new equipment in many applications [16]. Through experimentation, it was found that R32 produces better results in terms of higher COP and higher capacity [17]. However, different system components need to be optimized for a better R32 application. The main concern is the high compressor discharge temperature when using R32 at extreme cooling and heating conditions. High compressor discharge temperature also reduces the reliability of system operation due to the possibility of lubricating oil performance degradation [17]. A recent study on natural refrigerant options for residential heat pump water heaters states that R290a is a viable drop-in replacement for R134a, while R600a requires a larger compressor size to meet a similar heating capacity [18]. Significant reductions in refrigerant charge, along with lower condenser discharge temperatures are also additional benefits.

\section{Mobile air conditioning sector}

Until recently, R134a was the primary refrigerant for the mobile air conditioning systems in Europe, but in regard to the MAC Directive, which prohibits the use of refrigerants with a GWP of 150 or more in all new vehicles from January 2017, it is being replaced with R1234yf. This refrigerant is part of the HFO refrigerant group, which is widely recognized as the next generation of refrigerants because of their environmental friendliness (GWP < 10), cost-effectiveness, and great energy efficiencies [19]. One of the reasons why R1234yf is such a good alternative to R134a is the similarity of their thermophysical properties. A study on R134a substitutes also proposes R1234yf as a viable alternative, yet states that another HFO refrigerant - R1234ze(E) may perform even better under specific conditions [20]. However, it is worth noting that the particular study did not consider pressure drops in their analyses. Nevertheless, R1234ze(E) has found its application in various refrigerant mixtures, which have a lower potential of 
flammability risk because of their content in the mixture. A study on alternative low-GWP refrigerants in MAC systems [21] shows that R444A (R1234ze(E)/R152a/R32 - 83/5/12) and R445A (R1234ze(E)/R134a/R744 - 85/9/6) could be considered as alternatives to R1234yf for the air conditioning systems of large vehicles for which flammability is a major problem. Finally, Daimler AG has recently developed $\mathrm{CO}_{2}$ air conditioning systems which are, as of 2017 offered for the first time in their luxury class vehicles as a replacement for R134a [26].

\section{DISCUSSION AND RESULTS}

The F-gas Regulation has already made a substantial impact on various industry sectors and more changes are already underway. Moreover, it has triggered innovation in new technologies, especially the ones relying on natural refrigerants. The technology revolving around $\mathrm{CO}_{2}$ is of particular interest because it can achieve substantial additional energy efficiency benefits through a system that integrates heating, cooling and refrigeration. Also, component prices have also been affected. Prices regarding natural refrigerant-based units have fallen dramatically and have become comparable with those of equivalent HFC units. This has been particularly registered in the sector of commercial refrigeration, which has seen a strong growth in HFC-free technology. Finally, the EU legislation has also inspired governments around the world and is currently shaping the global industry.

\section{Total Equivalent Warming Impact}

The need to control emissions of greenhouse gases under the provisions of the Kyoto Protocol requires careful consideration and evaluation of energy consuming activities. TEWI is a measure of the relative impact on global warming (relative to $\mathrm{CO}_{2}$ ) of a specific refrigeration system during its operation. It is based on the total greenhouse gas emissions during the operation of the equipment and the subsequent disposal of the refrigerant at the end of life. TEWI takes into account both the direct and indirect emissions produced through the energy consumed in operating the equipment. Direct emissions refer to refrigerant released during the lifetime of the equipment, including unrecovered losses on final disposal, while indirect emissions are related to $\mathrm{CO}_{2}$ emissions from fossil fuels used to generate energy to operate the equipment throughout its lifetime [27]. Refrigerant leakage is imminent during maintenance and servicing due to a high pressure in the system compared to the ambient [28]. TEWI calculations depend on a number of assumptions regarding the performance of the equipment, properties of refrigerants and electricity generation efficiencies. The $\mathrm{CO}_{2}$ equivalent emissions from electricity generation depend on the region and the source of the electricity [29]. Therefore, the final values are subject to various deviations. In addition, for a TEWI comparison to be of real value, it must relate to systems of equal duty and function. Energy demand equivalent for manufacturing and transporting refrigerant and refrigeration equipment is excluded from TEWI calculations. Although it is possible to calculate the impact of these in TEWI terms, the values have been shown to be insignificant [27].

The method of calculating TEWI is provided below:

$$
\mathrm{TEWI}=\left(\mathrm{GWP} \times L_{\text {annual }} \times n\right)+\left[\mathrm{GWP} \times m \times\left(1-\alpha_{\text {rec }}\right)\right]+\left(n \times E_{\text {annual }} \times \beta\right)\left[\mathrm{kg} \mathrm{CO}_{2 \text { eq }}\right]
$$

where GWP is the global warming potential of refrigerant, relative to $\mathrm{CO}_{2}$ (GWP $\left.\mathrm{CO}_{2}=1\right), L_{\text {annual }}$ is the leakage rate per year $[\mathrm{kg}], n$ is system operating life [years], $m$ is refrigerant charge $[\mathrm{kg}], \alpha_{\text {rec }}$ is recovery/recycling factor from 0 to $1, E_{\text {annual }}$ is energy consumption per year [ $\mathrm{kWh}]$ and $\beta$ is indirect emission factor $\left[\mathrm{kg} \mathrm{CO}_{2} / \mathrm{kWh}\right]$. 
The first component of the equation represents the impact of leakage losses, the second - the impact of recovery losses, and the final one is the impact of energy consumption [30].

The calculation of a TEWI number is performed for an indirect refrigeration system with a known cooling load and energy efficiency ratio. Based on the given European Seasonal Energy Efficiency Ratio (ESEER) and cooling capacity from the manufacturer, the annual energy consumption has been calculated for an assumed number of full load hours of 1,200 per year for a total equipment lifetime of 15 years. Refrigerant emissions due to leakage and recovery factor have been based upon [27] where the leakage rate is estimated at 7\%, while the recovery factor is approximated to 0.9 [27]. The $\beta$ factor for $\mathrm{CO}_{2}$ equivalent emissions due to electricity used is the figure published by the Croatian Ministry of Construction and Physical Planning [31] at $0.23481 \mathrm{~kg} / \mathrm{kWh}$. Refrigerant charge has been determined according to the manufactures of the chillers with a similar cooling capacity $(\sim 650 \mathrm{~kW})$ :

- "Manufacturer Z" - R134a, 116 kg;

- "Manufacturer Z" - R410A, $154 \mathrm{~kg}$;

- "Manufacturer Y" - R290, $51 \mathrm{~kg}$;

- "Manufacturer X" - R717, $29 \mathrm{~kg}$.

The TEWI results calculated for refrigerants R134a, R410A, R290 and R717 are shown in Table 3.

Table 3. TEWI, ESEER's, energy consumption and annual leakage vs. different types of refrigerants

\begin{tabular}{ccccccc}
\hline Refrigerant & ESEER & $E_{\text {annual }}[\mathrm{kWh}]$ & GWP & $m[\mathrm{~kg}]$ & $L_{\text {annual }}[\mathrm{kg}]$ & TEWI $\left[\mathrm{kg} \mathrm{CO}_{2 \mathrm{eq}}\right]$ \\
\hline R134a & 4.99 & 156,313 & 1,430 & 116 & 8.12 & 723,978 \\
R410A & 4.92 & 158,537 & 1,980 & 154 & 10.78 & 909,049 \\
R290 & 4.96 & 157,258 & 3 & 51 & 3.57 & 554,062 \\
R717 & 5.01 & 155,689 & 0 & 29 & 2.03 & 548,360 \\
\hline
\end{tabular}

The impact of the relative emissions associated with the total energy consumption, leakage and recovery losses are shown in Figure 1.

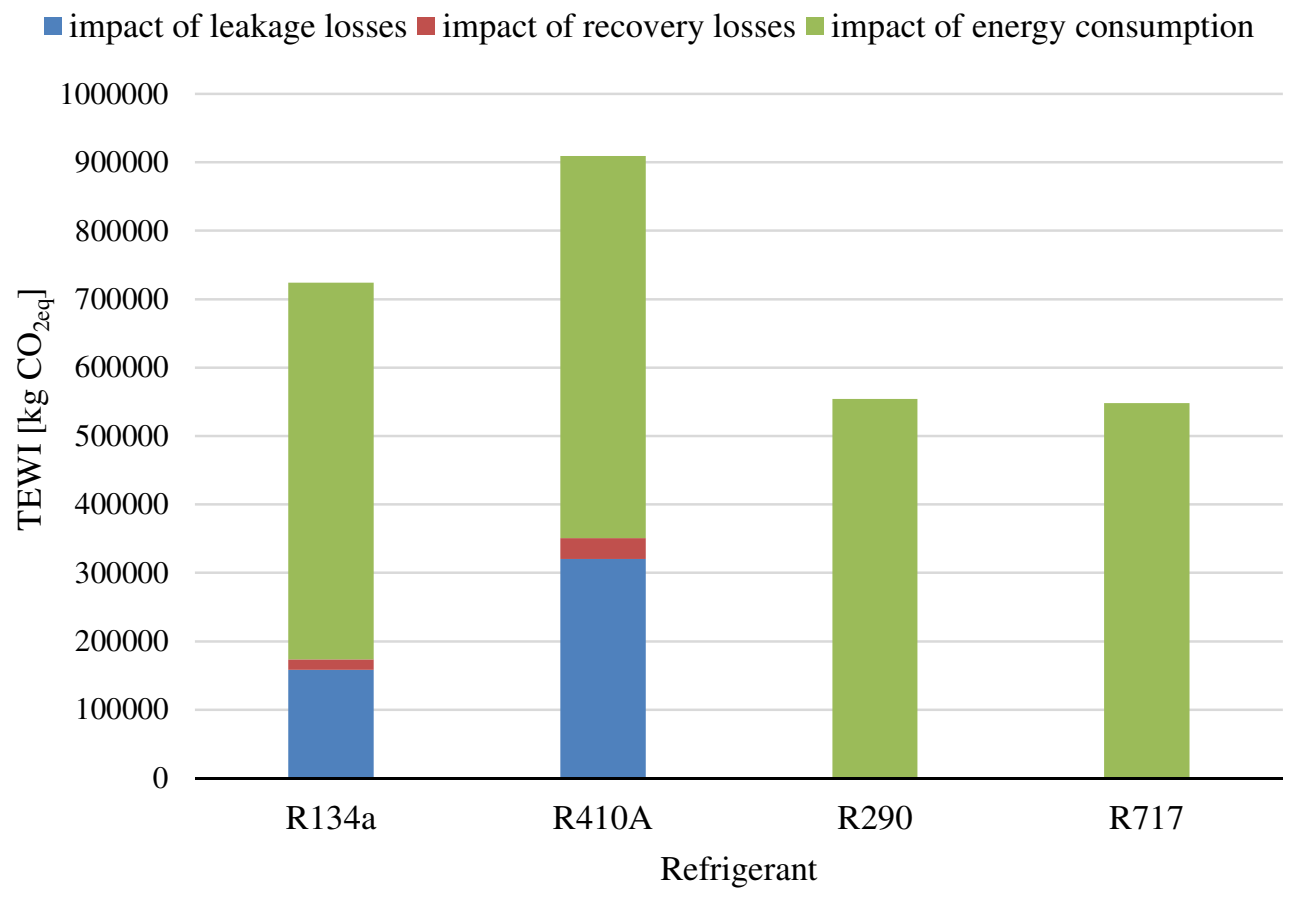

Figure 1. Detailed TEWI calculations for different types of refrigerant 
It is apparent that the emissions are the highest when the system contains fluorinated refrigerants. They are the highest for R410A due to the biggest refrigerant charge in combination with the largest GWP value. On the other hand, natural refrigerants have the most environmentally favourable results because of a variety of factors. Smaller system charges, coupled with the fact that the GWP values are near zero, makes their direct impact on the global warming practically non-existent. However, results also indicate that most of the emissions refer to the indirect impact, and due to the negligible differences between annual energy consumptions, those are mutually comparable for the refrigerants considered. A similar study on alternative refrigerants presented similar results [32], favouring refrigerants from the HC group over the HFC group in terms of total TEWI values.

\section{CONCLUSIONS}

This paper gives a comparison of basic properties and future potential of natural and fluorinated refrigerants across various industry sectors. Their application is placed in the context of the F-gas regulation of which proposals and conclusions clearly state that there are reliable and effective alternatives with low-GWP values that can be applied for various applications. The core of the Regulation is on the gradual reductions and the proposed ban on the use of certain fluorinated refrigerants, but more importantly, the emphasis on using natural refrigerants. Certain industry sectors, such as the sector of industrial refrigeration, have already adapted to the Regulation due to its long history of using natural refrigerants, while others, like the sector of commercial refrigeration, have undergone major changes since they introduced new $\mathrm{CO}_{2}$ based systems. $\mathrm{CO}_{2}$ technology looks very promising and shows that the industry was able to overcome the technical challenges related to the lack of awareness. Furthermore, a fairly new HFO refrigerant group is mentioned, which has already taken the lead in the mobile air conditioning systems due to its favourable environmental properties and cost-effectiveness.

In addition, the TEWI number methodology is presented for a cooling plant with a known cooling load. The results show that the natural refrigerants have a negligible direct environmental impact due to near zero GWP values, while HFC's have a significantly higher impact, mostly because of much higher GWP, but also due to bigger system charges. Of the tested refrigerants, the highest emissions are for the R410A system, which has a $68 \%$ higher total emission than the one using R717. Moreover, there is also a significant indirect impact on global warming for all types of refrigerants because of large amounts of annual energy consumption which suggests that there is an urgent need for further research into environmentally friendly energy generation and system performance efficiency. Finally, due to the negligible annual energy consumption differences between the said refrigerants, the running costs are comparable.

\section{NOMENCLATURE}

$c_{\mathrm{p}}$
$E_{\text {annual }}$
$L_{\text {annual }}$
$m$
$n$
$r$

\section{Greek letters}

$\begin{array}{ll}\alpha_{\text {rec }} & \text { recovery/recycling factor } \\ \beta & \text { indirect emission factor } \\ \lambda & \text { liquid thermal conductivity }\end{array}$

$$
\begin{aligned}
& \text { specific heat capacity } \\
& \text { energy consumption per year } \\
& \text { leakage rate per year } \\
& \text { refrigerant charge } \\
& \text { system operating life } \\
& \text { specific latent heat }
\end{aligned}
$$

$$
\begin{gathered}
{[\mathrm{kJ} / \mathrm{kgK}]} \\
{[\mathrm{kWh}]} \\
{[\mathrm{kg}]} \\
{[\mathrm{kg}]} \\
{[\text { years] }} \\
{[\mathrm{kJ} / \mathrm{kg}]}
\end{gathered}
$$

[-]

$[\mathrm{kg} \mathrm{CO} / \mathrm{kWh}]$

[W/mK] 


\begin{tabular}{llc}
\hline$\mu$ & dynamic viscosity & {$[\mathrm{Pas}]$} \\
$\rho$ & liquid density & {$\left[\mathrm{kg} / \mathrm{m}^{3}\right]$}
\end{tabular}

\section{Abbreviations}

$\begin{array}{ll}\text { CFC } & \text { Chlorofluorocarbons } \\ \text { COP } & \text { Coefficient of Performance } \\ \text { ESEER } & \text { European Seasonal Energy Efficiency Ratio } \\ \text { GWP } & \text { Global Warming Potential } \\ \text { HCFC } & \text { Hydrochlorofluorocarbons } \\ \text { HFC } & \text { Hydrofluorocarbons } \\ \text { HFO } & \text { Hydrofluoro-olefins } \\ \text { ODP } & \text { Ozone Depleting Potential } \\ \text { TEWI } & \text { Total Equivalent Warming Impact }\end{array}$

\section{REFERENCES}

1. Eickhout, B., F-Gas Regulation Shaking up the HVAC\&R Industry, Report, Bruxelles, Belgium, 2016.

2. Regulation (EU) No. 517/2014 of the European Parliament and of the Council on Fluorinated Greenhouse Gases and Repealing Regulation (EC) No. 842/2006, 2014.

3. Colombo, I., Maidment, G. G. and Cowan, D., Whole Life Emission for Air to Water Heat Pumps: An Investigation, Proceedings of the $24^{\text {th }}$ International Congress of Refrigeration, ID 748, Yokohama, Japan, 2015.

4. Mota-Babiloni, A., Navarro-Esbri, J., Barragan-Cervera, A., Moles, F. and Peris, B., Analysis Based on EU Regulation No 517/2014 of New HFC/HFO Mixtures as Alternatives of High GWP Refrigerants in Refrigeration and HVAC Systems, International Journal of Refrigeration, Vol. 52, pp 21-31, 2015, https://doi.org/10.1016/j.ijrefrig.2014.12.021

5. Bolaji, B. O. and Huan, Z., Ozone Depletion and Global Warming: Case for the Use of Natural Refrigerant - A Review, Renewable and Sustainable Energy Reviews, Vol. 18, pp 49-54, 2013, https://doi.org/10.1016/j.rser.2012.10.008

6. Mota-Babiloni, A., Navarro-Esbri, J., Barragan-Cervera, A., Moles, F., Peris, B. and Verdu, G., A Review of Refrigerant R1234ze(E) Recent Investigations, Applied Thermal Engineering, Vol. 95, pp 211-222, 2015, https://doi.org/10.1016/j.applthermaleng.2015.09.055

7. Bedoić, R. and Filipan, V., Heating Performance Analysis of a Geothermal Heat Pump Working with Different Zeotropic and Azeotropic Mixtures, J. Sustain. Dev. Energy Water Environ. Syst., Vol. 6, No. 2, pp 240-253, 2018, https://doi.org/10.13044/j.sdewes.d5.0189

8. Colbourne, D. and Suen, K. O., Comparative Evaluation of Risk of a Split Air Conditioner and Refrigerator Using Hydrocarbon Refrigerants, International Journal of Refrigeration, Vol. 59, pp 295-303, 2015, https://doi.org/10.1016/j.ijrefrig.2015.06.026

9. Shaik, V. S. and Ashok Babu, P. T., Theoretical Performance Investigation of Vapour Compression Refrigeration System Using HFC and HC Refrigerant Mixtures as Alternatives to Replace R22, Proceedings of the International Conference on Recent Advancement in Air Conditioning and Refrigeration (RAAR), Bhubaneswar, Odisha, India, 2016.

10.Bortolini, M., Gamberi, M., Gamberini, R., Graziani, A., Lolli, F. and Regattieri, A., Retrofitting of R404a Commercial Refrigeration Systems Using R410A and R407F Refrigerants, International Journal of Refrigeration, Vol. 55, pp 142-152, 2015, https://doi.org/10.1016/j.ijrefrig.2015.02.015

11.Makhnatch, P., Replacements for R404A, Deparment of Energy Technology, KTH Royal Institute of Technology, KYLA+ Värmepumpar \#7, 2014. 
12.Mota-Babiloni, A., Navarro-Esbri, J., Peris, B., Moles, F. and Verdu, G., Experimental Evaluation of R448A as R404A Lower-GWP Alternative in Refrigeration Systems, Energy Conversion and Management, Vol. 105, pp 756-762, 2015, https://doi.org/10.1016/j.enconman.2015.08.034

13.Makhnatch, P., Mota-Babiloni, A., Rogstam, J. and Khodabandeh, R., Retrofit of Lower GWP Alternative R449A into an Existing R404A Indirect Supermarket Refrigeration System, International Journal of Refrigeration, Vol. 76, pp 184-192, 2017, https://doi.org/10.1016/j.ijrefrig.2017.02.009

14.Mastrullo, R., Mauro, A. W., Menna, L. and Vanoli, G. P., Replacement of R404A with Propane in a Light Commercial Vertical Freezer: A Parametric Study of Performances for Different System Architectures, Energy Conversion and Management, Vol. 82, pp 54-60, 2014, https://doi.org/10.1016/j.enconman.2014.02.069

15.Sethi, A. and Motta, S. Y., Low GWP Refrigerants for Air Conditioning and Chillers Applications, Proceedings of the $16^{\text {th }}$ International Refrigeration and Air Conditioning Conference at Purdue, West Lafayette, Indiana, USA, 2016.

16.Pham, H. and Rajendran, R., R32 and HFOs as Low-GWP Refrigerants For Air Conditioning, Proceedings of the 2012 International Refrigeration and Air Conditioning Conference at Purdue, West Lafayette, Indiana, USA, 2012.

17.Hwang, Y., Xu, X. and Radermacher, R., Performance Comparison of R410A and R32 in Vapor Injection Cycles, International Journal of Refrigeration, Vol. 36, No. 3, pp 892-903, 2013, https://doi.org/10.1016/j.ijrefrig.2012.12.010

18.Sanchez, D., Cabello, R., Llopis, R., Arauzo, I., Catalan-Gil, J. and Torella, E., Energy Performance Evaluation of R1234yf, R1234ze(E), R600a, R290, and R152a as Low-GWP Alternatives, International Journal of Refrigeration, Vol. 74, pp 269-282, 2016, https://doi.org/10.1016/j.ijrefrig.2016.09.020

19.Nawaz, K., Shen, B., Elatar, A., Baxter, V. and Abdelaziz, O., R290 (Propane) and R600a (Isobutane) as Natural Refrigerants for Residential Heat Pump Water Heaters, Applied Thermal Engineering, Vol. 127, pp 870-883, 2017, https://doi.org/10.1016/j.applthermaleng.2017.08.080

20.Janković, Z., Atienza, S. A. and Suarez, M. A. J., Thermodynamic and Heat Transfer Analyses for R1234yf and R1234ze(E) as Drop-in Replacements for R134a in a Small Power Refrigerating System, Applied Thermal Engineering, Vol. 80, pp 45-54, 2015, https://doi.org/10.1016/j.applthermaleng.2015.01.041

21.Devecioglu, A. G. and Oruc, V., An Analysis on the Comparison of Low-GWP Refrigerants to Alternatively Use in Mobile Air-conditioning Systems, Thermal Science and Engineering Progress, Vol. 1, pp 1-5, 2017, https://doi.org/10.1016/j.tsep.2017.02.002

22.ASHRAE Handbook, Refrigeration, Atlanta, Georgia, USA, 2014.

23.ASHRAE Handbook, Fundamentals, Atlanta, Georgia, USA, 2017.

24.ASHRAE Journal, 10/2016.

25.ASHRAE Journal, 08/2016.

26.https://www.daimler.com/sustainability/product/further-environmental-technologies/co 2-air-conditioning-system.html, [Accessed: 01-April-2017]

27. Australian Institute of Refrigeration, Air Conditioning and Heating (AIRAH), Methods of Calculating Total Equivalent Warming Impact (TEWI), Best Practice Guidelines, 2012.

28.Islam, A., Srinivasan, K., Thu, K. and Baran Saha, B., Assessment of Total Equivalent Warming Impact (TEWI) of Supermarket Refrigeration Systems, International Journal of Hydrogen Energy, Vol. 42, No. 43, pp 26973-26983, 2017, https://doi.org/10.1016/j.ijhydene.2017.07.035

29.Bengtsson, P. and Eikevik, T., Reducing the Global Warming Impact of a Household Heat Pump Dishwasher Using Hydrocarbon Refrigerants, Applied Thermal 


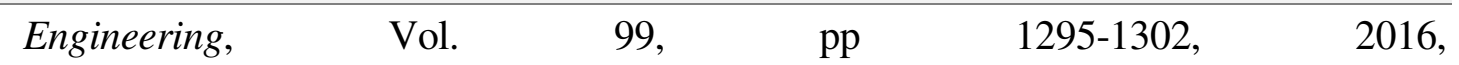
https://doi.org/10.1016/j.applthermaleng.2016.02.018

30.Drughean, L., Ilie, A., Girip, A. and Teodorescu, D., Environmental Impact of Possible Replacements for R22, Proceedings of the $24^{\text {th }}$ International Congress of Refrigeration, ID 182, Yokohama, Japan, 2015.

31.http://www.mgipu.hr/doc/EnergetskaUcinkovitost/FAKTORI_primarne_energije.pdf, [Accessed: 01-April-2017]

32.Antunes, A. H. P. and Filho, E. P. B., Experimental Investigation on the Performance and Global Environmental Impact of a Refrigeration System Retrofitted with Alternative Refrigerants, International Journal of Refrigeration, Vol. 70, pp 119-127, 2016, https://doi.org/10.1016/j.ijrefrig.2016.06.027 